\title{
Heat and Mass Transfer in a Copper Oxy-Chloride Spray Reactor for Thermochemical Hydrogen Production
}

\author{
A. Odukoya ${ }^{1 *}$, G. F. Naterer ${ }^{2}$, M. A. Rosen ${ }^{3}$ \\ ${ }^{1,2}$ Memorial University of Newfoundland, St. John's, Newfoundland, Canada \\ ${ }^{3}$ University of Ontario Institute of Technology (UOIT), Oshawa, Ontario, Canada
}

\begin{abstract}
A new predictive model is developed in this paper to analyze the height of the reactor for continuous production of copper oxy-chloride in the thermochemical $\mathrm{Cu}-\mathrm{Cl}$ cycle for hydrogen production. The volumetric phase fraction is used to develop an energy balance and integrated spatially to determine the inlet temperature of nitrogen and steam mixtures for continuous production of copper oxy-chloride. The effects of the ratio of mixing power to mass of the suspended particle, the ratio of interfacial surface area of the gas film to the volume of liquid, and diameter of the steam/nitrogen bubble in the reactor, on the height of the reactor are reported for a production capacity of $3 \mathrm{~kg}$ of hydrogen per day. Results indicate that a smaller ratio of interfacial surface area to volume of liquid significantly reduces the height of the reactor.
\end{abstract}

\section{Introduction}

One of the major technical challenges of the $\mathrm{Cu}-\mathrm{Cl}$ cycle for thermochemical hydrogen production is the hydrolysis step to produce copper oxy-chloride $\left(\mathrm{Cu}_{2} \mathrm{OCl}_{2}\right)$. Recent advances in the $\mathrm{Cu}-\mathrm{Cl}$ cycle have shown that in order to improve the efficiency of the cycle, the drying of the $\mathrm{CuCl}_{2}$ particles from the electrolysis step and the hydrolysis step to produce $\mathrm{Cu}_{2} \mathrm{OCl}_{2}$ should be combined into one process. In order to achieve this objective, a spray roaster was determined as

\footnotetext{
${ }^{1 *}$ Research Project Engineer, Faculty of Engineering and Applied Science, Memorial University, St. John's, Newfoundland, 240 Prince Phillip Drive, St. John’s, NL Canada A1B 3X5, Email: aodukoya@mun.ca, Phone:1-709-864-2395, Fax: (709) 864-8975

${ }^{2}$ Professor and Dean, Faculty of Engineering and Applied Science, Memorial University of Newfoundland, St. John's, NL, A1B 3X5

${ }^{3}$ Professor of Mechanical Engineering, UOIT, 2000 Simcoe Street North, Oshawa, Ontario, Canada, L1H 7K4
} 
an effective means to integrate the cycle and avoid the dual processes. This paper investigates the heat and mass transfer processes of the reaction kinetics in the spray roaster to produce $\mathrm{Cu}_{2} \mathrm{OCl}_{2}$.

Extensive experimental studies were conducted by researchers at the Argonne National Laboratory (ANL) for a spray reactor $[1,2]$ to determine the mass flow rate of steam required to produce $\mathrm{Cu}_{2} \mathrm{OCl}_{2}$, using a mixture of argon/steam to supply heat to the reactor. The results indicated that $100 \%$ yields of $\mathrm{Cu}_{2} \mathrm{OCl}_{2}$ were achieved when an ultrasonic nozzle is used to inject the reactants into the reactor at about $375{ }^{\circ} \mathrm{C}$. The products were examined using X-ray diffraction (XRD) and scanning electron microscope (SEM) images. The results also indicated that a concurrent flow into the reactor chamber of $\mathrm{CuCl}_{2}$ slurry and steam was preferable for efficient production of $\mathrm{Cu}_{2} \mathrm{OCl}_{2}$.

The excess steam required by spray reactor experiments conducted by ANL to produce $\mathrm{Cu}_{2} \mathrm{OCl}_{2}$ reduces the efficiency of the system. The cost of the plant increases with an increasing steam requirement to achieve continuous production of $\mathrm{Cu}_{2} \mathrm{OCl}_{2}$. Pope et al. [3] performed experimental studies to investigate the possibility of using nitrogen to reduce the steam requirement of the hydrolysis reaction in a fluidized bed reactor. The experimental results reported by Pope et al. [3] indicated that nitrogen will reduce the steam consumption, but the yield of $\mathrm{Cu}_{2} \mathrm{OCl}_{2}$ was not adequate for further development of the fluidized bed reactor. The gas film layer formed around the solid $\mathrm{CuCl}_{2}$ particles during the hydrolysis reaction may be responsible for the incomplete conversion observed in the hydrolysis reaction.

This paper modifies the reaction by using nitrogen in the concurrent flow spray reactor proposed by Ferrandon et al. [4, 5] to achieve continuous production of $\mathrm{Cu}_{2} \mathrm{OCl}_{2}$. Past studies have indicated that the chemical conversion effectiveness decreases as reactants are consumed [3]. 
Ferrandon et al. [6] reported that the conversion extent of the solid hydrolysis reactant indicated an optimal conversion of $4 \mathrm{~mol}$ to $15 \mathrm{~mol}$ of steam per mol of $\mathrm{HCl}$ produced [7]. Further studies [8] indicated thermodynamic an optimal temperature of the hydrolysis reactor to be approximately $375^{\circ} \mathrm{C}$.

The numerical investigation in this study determines the molar flow rate of $\mathrm{N}_{2}$ to sustain the reaction. The study also investigates the reactor size required to produce $3 \mathrm{~kg}$ of $\mathrm{H}_{2} / \mathrm{day}$, which is the target production rate of a pilot-scale system under construction at the University of Ontario Institute of Technology (UOIT). This paper investigates the heat and mass transfer mechanisms of the spray reactor to reduce the consumption of steam and continuously produce $3 \mathrm{~kg}$ of $\mathrm{H}_{2} /$ day. For an integrated $\mathrm{Cu}-\mathrm{Cl}$ cycle with a hydrogen production rate of $3 \mathrm{~kg} / \mathrm{day}$, the corresponding required capacity of copper oxychloride production is about $13.3 \mathrm{~kg} /$ day in the spray reactor. The primary goals of this paper are to gain better understanding and insight into the effects of temperature, particle size, mixing power, interfacial reaction surface, and bubble dispersion in the spray reactor.

\section{System Description}

The hydrolysis reaction can be represented by the following reaction:

$$
2 \mathrm{CuCl}_{2(a q)}+\mathrm{H}_{2} \mathrm{O}_{(g)} \rightarrow \mathrm{Cu}_{2} \mathrm{OCl}_{2(s)}+2 \mathrm{HCl}_{(g)}
$$

The products are fed into the thermolysis $\left(\mathrm{Cu}_{2} \mathrm{OCl}_{2}\right)$ reactor and the electrolytic cell $(\mathrm{HCl})$. The efficient operation of the electrolysis process requires that the concentration of $\mathrm{HCl}$ is between 6 and 11 mol. Using the concurrent flow reactor suggested by Ferrandon et al. [5], the steam is injected with $\mathrm{Ar}$ at a flow rate of $400 \mathrm{~mL} / \mathrm{min}$ at $370{ }^{\circ} \mathrm{C}$ for continuous production of $\mathrm{Cu}_{2} \mathrm{OCl}_{2}$. A steam to $\mathrm{CuCl}_{2}$ ratio of 20 produced the desired amount of $\mathrm{Cu}_{2} \mathrm{OCl}_{2}$ for the spray reactor. 
Numerical investigations for a fluidized bed reactor reported by Daggupatti [9] reported a ratio of 17:1 for the steam to $\mathrm{CuCl}_{2}$ for the reactor operating between $350{ }^{\circ} \mathrm{C}$ and $400{ }^{\circ} \mathrm{C}$.

The spray reactor analysis is a complex transport problem involving atomization, heat and mass transfer, and phase change. The $\mathrm{CuCl}_{2}$ slurry is sprayed into the reactor at about $150{ }^{\circ} \mathrm{C}$, while the nitrogen/steam mixture is injected at about $375^{\circ} \mathrm{C}$. The path of the reaction is depicted in Fig. 1 for the particle. The analysis assumes that when slurry enters the reactor, the high temperature mixture of steam and nitrogen evaporates the water in the slurry so the steam concentration decreases accordingly in Fig. 1. The steam subsequently diffuses down a concentration gradient in Fig. 1 through the film surrounding the surface of the particle. The reaction rate is slower within the core of the solid particle as the reaction takes place on the solid surface. The gaseous surface diffuses back through the film again down a concentration gradient and through the main body of the slurry.

\section{Reaction Rate Formulation}

Considering a multiphase concurrent flow configuration in Fig. 2, the kinetic equations for the chemical reaction are used to determine the height of the reactor. It is assumed that the reaction rate is slower than the mass transfer. The reaction rate is best measured in terms of unit volume of the reacting phase rather than the interfacial surface between phases. The material balance for the reactor can be expressed as follows:

$$
G d Y=-\frac{L d X}{b}=-r_{y} d h=\frac{\text { moles of Y reacted }}{\text { (volume of liquid)(time) }}\left(\frac{\text { volume of liquid phase }}{\text { total volume }}\right)(\text { Height of element })
$$


where $Y$ is the $\mathrm{CuCl}_{2}$ slurry, $X$ is steam, $G$ is the molar flow rate of the inert gas in the gas phase, $L$ is the molar flow rate of the inert gas in the liquid phase, $r_{y}$ is the reaction rate, $h$ is the height of the reactor, and $b$ is the moles of steam consumed.

The model assumes that the slurry is insoluble in the steam, and the amount of the unreacted steam in the liquid is small compared to the steam in the gas phase. Each mole of reacting steam is replaced by fresh steam sprayed in the reactor. Integrating over the control volume, the height of the reactor can be estimated by

$$
h=\frac{G}{f} \int_{y_{1}}^{y_{2}}\left[\frac{d Y}{r_{y}}\right]=-\frac{L}{b f} \int_{x_{1}}^{x_{2}} \frac{d X}{r_{y}}
$$

where $f$ is the volume fraction of the phase in which the reaction occurs, and $d Y$ and $d X$ can be determined with respect to the inert gas in the reaction as follows:

$$
\begin{aligned}
& d Y=\frac{p_{N_{2}} d p_{\mathrm{H}_{2} \mathrm{O}}-p_{\mathrm{H}_{2} \mathrm{O}} d p_{\mathrm{N}_{2}}}{\left(p_{\mathrm{N}_{2}}\right)^{2}} \\
& d X=\frac{C_{N_{2}} d C_{\mathrm{CuCl}_{2}}-C_{\mathrm{CuCl}_{2}} d C_{\mathrm{N}_{2}}}{\left(C_{\mathrm{N}_{2}}\right)^{2}}
\end{aligned}
$$

Here, $p$ and $C$ are mole fractions of the reacting species. The reaction rate $r_{y}$ is determined by combining the reaction rates across each boundary in the process as identified in Fig. 2 and the total rate is determined as:

$$
-r_{y}=\frac{1}{\frac{1}{k_{s} a_{i}}+\frac{H}{k_{l} a_{i}}+\frac{H}{k_{l} a_{s}}+\frac{H}{k_{l c} a_{s}}} p_{s}
$$


where $H$ is Henry's constant (the ratio of pressure to mole fraction of the reacting species), $a_{i}$ is the ratio of interfacial surface to the volume of the liquid, and $a_{s}$ is the ratio of the suspended $\mathrm{CuCl}_{2}$ particle to the volume of liquid. These ratios are usually experimentally determined [10].

The mass transfer coefficient varies for the gas-liquid interface, gas-solid interface, and liquid-solid interface. The mass transfer coefficient for the gas film is determined as follows [10]:

$$
k_{s l}=\frac{\left(2+1.1\left[S c^{1 / 3} \mathrm{Re}^{0.6}\right]\right) D_{k}}{d_{p}}
$$

where $D_{k}$ is the molecular diffusion of the gas phase, $S c$ is the Schmidt number, $R e$ is Reynolds number of the flow, and $d_{p}$ is diameter of the particle. The gas-liquid mass transfer coefficient is determined as [10]:

$k_{l}=\frac{\varepsilon D_{K}^{4} d_{b}^{2} \rho_{l}}{\mu_{l}}$

where $\varepsilon$ is the ratio of the stirring power to the mass of suspension, $\rho_{l}$ is the density of the fluid, $d_{b}$ is the diameter of the gas bubble, and $\mu_{l}$ is the viscosity of the liquid. The mass transfer coefficient of the solid interface is estimated by replacing the diameter of the bubble in Eq. (8) with the diameter of the particle.

The diffusion coefficient used for this study is adopted from correlations developed by Tapio et al. [10] and determined using the following expression:

$$
D_{k}=\frac{1-x_{i}}{\sum_{k=1}^{N} \frac{x_{k}\left(p\left[v_{i}^{1 / 3}+v_{k}^{1 / 3}\right]^{2}\right)}{T^{1.75}\left(M_{i}+M_{k}\right)^{0.5} \times 10^{-7}}}
$$


where $T$ is the temperature $(\mathrm{K}), p$ is the pressure (atm), $M$ is the molecular mass $(\mathrm{g} / \mathrm{mol})$, and $v$ is the volume of the molecule.

\section{Formulation of Reaction Temperature}

The energy balance is established for each phase accounting for interactions between phases. This analysis assumes that the temperature is equal in each phase for a small elemental volume in the reactor. An elemental volume in the reactor is $\Delta V_{R}$, gas phase $\Delta V_{S G}$, and the surface element for the gas-solid interface with surface area $\Delta A$. The energy balance can be written as:

$\int_{0}^{h} R\left(-\Delta H_{r}\right) d z \Delta A+R\left(-\Delta H_{r}\right) \Delta V_{S G}+R\left(\Delta H_{r}\right) \Delta V_{L}=\Delta \dot{Q}+m_{l} c_{p l} \Delta T+m_{g} c_{p g} \Delta T+m_{s} c_{p s} \Delta T$

where $\Delta \dot{Q}$ is the chemical reaction heat effect for the elemental fluid in the reacting phase. Using the mass balance and volume fractions, Eq. (10) can be written as:

$\int_{0}^{h} R\left(-\Delta H_{r}\right) d z a_{v} \Delta V_{r}+R\left(-\Delta H_{r}\right) \beta_{l} \Delta V_{r}+R\left(\Delta H_{r}\right)\left(1-\beta_{l}+\beta_{g}\right) \Delta V_{r}=U \Delta s\left(T-T_{c}\right)+\left(m_{l} c_{p l}+m_{g} c_{p g}+m_{s} c_{p s}\right) \Delta T(11)$

where $\Delta s=\Delta V_{R}\left(\frac{s}{V_{R}}\right), \beta_{l}=\frac{\Delta V_{S G}}{\Delta V_{R}}, a_{v}=\frac{\Delta A}{\Delta V_{R}}$ and $U$ is the overall heat transfer coefficient. Also, $C_{p}$ is the specific heat capacity, and $m$ is the mass flow rate of each phase. The rate of temperature change across the elemental control volume can be determined from Eq. (11):

$$
\frac{d T}{d V_{R}}=\frac{\int_{0}^{h} R\left(-\Delta H_{r}\right) d z a_{v}+R\left(-\Delta H_{r}\right) \beta_{l}+R\left(\Delta H_{r}\right)\left(1-\beta_{l}+\beta_{g}\right)}{\left(m_{l} c_{p l}+m_{g} c_{p g}+m_{s} c_{p s}\right)}
$$

Eq. (12) is used to determine the temperature over the entire reactor height based on a specific temperature for the reactor wall, steam and slurry injected into the reactor. The temperature and mass transfer formulation can be combined to analyze the spray reactor. Previous studies by 
Venkata et al. [11] have validated numerical predictions of steam conversion variations with temperature in the hydrolysis reaction through comparisons against experimental data. In the next section, results of the previous models will be presented and discussed.

\section{Results and Discussion}

The numerical model is developed to predict the height of the reactor required to generate $3 \mathrm{~kg}$ of $\mathrm{H}_{2}$ per day using the thermochemical $\mathrm{Cu}-\mathrm{Cl}$ cycle. The assumptions used for the numerical model are outlined in Table 1. Matlab is used to solve the coupled chemical reaction model and the energy balance model to predict the reactor height and temperature required for continuous production of $\mathrm{Cu}_{2} \mathrm{OCl}_{2}$.

The reactor is maintained between $370{ }^{\circ} \mathrm{C}$ and $400{ }^{\circ} \mathrm{C}$ during the simulation, as past studies $[4,6,12]$ indicate the optimum yield of $\mathrm{Cu}_{2} \mathrm{OCl}_{2}$ occurs within this temperature range. The numerical model is used to determine the required supply temperature of nitrogen gas to sustain the reaction. Increasing the molar flow rate of $\mathrm{N}_{2}$ reduces the inlet temperature required for production of $\mathrm{Cu}_{2} \mathrm{OCl}_{2}$ as shown in Fig. 3. Based on the analysis, a steam/ $\mathrm{N}_{2}$ ratio of 7 will sustain the reaction. This significantly reduces the space and cost of integrating the $\mathrm{Cu}-\mathrm{Cl}$ cycle. When the molar flow rate of $\mathrm{N}_{2}$ is between 8 and $10 \mathrm{~mol} / \mathrm{s}$, the reactor temperature has less than a $10 \%$ difference in the required inlet temperature and the heat can be provided from waste heat recovered in the cycle. This can greatly improve the efficiency of the $\mathrm{Cu}-\mathrm{Cl}$ cycle.

The ratio of mixing power to mass of the suspension has a significant effect on the height of the reactor as shown in Fig. 4. At a mixing power ratio of 0.1 , when the radius of the reactor is doubled, the height of the reactor required for continuous production of $\mathrm{Cu}_{2} \mathrm{OCl}_{2}$ reduces by a third of the original height. This effect is exponentially reduced as the mixing power increases. 
Experimental measurements are required to determine the actual mixing power required for a specific reactor height. Experiments will be performed at UOIT to verify the results obtained by this model. The results will be used to scale-up the reactor for integration of the $\mathrm{Cu}-\mathrm{Cl}$ cycle.

Increasing the ratio of the interfacial surface area of the solid to volume of the liquid increases the height of the reactor as shown in Fig. 5. The effect at a radius of $0.15 \mathrm{~m}$ is more pronounced, as the height of the reactor increases by about a meter. Increasing the height of the reactor may reduce the residence time in the reactor, which is favorable for integration. A compromise must be made due to space limitations for the pilot-scale. The size of the particle sprayed into the reactor will have an effect on $a_{i}$, reducing the particle size, which reduces the ratio and size of the reactor. A reduced particle size also reduces the residence time in the reactor.

During the actual reaction in the $\mathrm{Cu}-\mathrm{Cl}$ cycle, the process involves simultaneous decomposition and hydrolysis reaction steps. Previous studies found that excess steam may react with chlorine formed during the decomposition step within the product layer. The chlorine reaction is a homogeneous gas phase reaction, coupled with a gas-solid heterogeneous reaction. A "uniform-conversion" model or "shrinking-core" model can be used for the prediction of conversion of cupric chloride in the hydrolysis reaction. These factors affect the actual reaction kinetics and process thermodynamics in the hydrolysis reaction.

The diameter of the gas bubble has a significant effect on the height of the reactor between 2 and $6 \mu \mathrm{m}$ as shown in Fig. 6. The slurry particle size is kept constant at $250 \mu \mathrm{m}$ for the simulation in this study. Increasing the gas bubble diameter increases the surface area for the reaction, subsequently reducing the residence time in the reactor. Smaller gas bubbles will travel faster across the control volume, not allowing sufficient time for the reaction to occur. The increase in 
the height of reactor is due to the same residence time in the reactor model. Experimental measurements will be performed to determine the bubble size for a specific reactor height to allow for the complete reaction. Although this model only performs a numerical solution for each parameter of interest, a numerical routine using a heuristic technique will be developed to optimize all the parameters required for a specific reactor height.

\section{Conclusions}

This paper presents a new predictive model for analyzing the required height and inlet temperature of steam/ $\mathrm{N}_{2}$ for a spray reactor used for the production of $\mathrm{Cu}_{2} \mathrm{OCl}_{2}$ in the $\mathrm{Cu}-\mathrm{Cl}$ cycle of thermochemical hydrogen production. The predicted results indicate the inlet temperature may vary between $1,000 \mathrm{~K}$ and $400 \mathrm{~K}$ depending on the molar flow rate of hydrogen and the radius of the reactor. Also, the analysis indicates that increasing the mixing power and reducing the ratio of interfacial surface area to volume of liquid significantly reduces the height of the reactor. These results will be used to design the spray reactor to integrate the electrolysis and copper decomposition reactors of the $\mathrm{Cu}-\mathrm{Cl}$ cycle.

\section{Acknowledgements}

Support of this research from Atomic Energy of Canada Limited, the Ontario Research Excellence Fund and the Natural Sciences and Engineering Research Council of Canada is gratefully acknowledged.

\section{$\underline{\text { References }}$}

[1] G. Naterer, S. Suppiah, M. Lewis, K. Gabriel, I. Dincer, M.A. Rosen, M. Fowler, G. Rizvi, E. Easton, B. Ikeda, Recent Canadian advances in nuclear-based hydrogen production and the thermochemical Cu-Cl cycle, Int. J. Hydrogen Energy. 34 (2009) 2901-2917. 
[2] M.A. Lewis, Update on the Cu-Cl cycle R\&D effort. Workshop of the ORF Hydrogen Project at AECL Chalk River Laboratories, 17 (2008) 25-33-Chalk River, Ontario.

[3] K. Pope, G. Naterer, Z. Wang, Nitrogen carrier gas flow for reduced steam requirements of water splitting in a packed bed hydrolysis reactor, Exp. Therm. Fluid Sci. 44 (2013) 815-824.

[4] M. Ferrandon, M. Lewis, D. Tatterson, A. Zdunek, Status of the development effort for the thermochemical Cu-Cl cycle, 30 (2008) 1-87.

[5] M.S. Ferrandon, M.A. Lewis, D.F. Tatterson, A. Gross, D. Doizi, L. Croize, V. Dauvois, J. Roujou, Y. Zanella, P. Carles, Hydrogen production by the $\mathrm{Cu}-\mathrm{Cl}$ thermochemical cycle: investigation of the key step of hydrolysing $\mathrm{CuCl} 2$ to $\mathrm{Cu} 2 \mathrm{OCl} 2$ and $\mathrm{HCl}$ using a spray reactor, Int. J. Hydrogen Energy. 35 (2010) 992-1000.

[6] M.S. Ferrandon, M.A. Lewis, F. Alvarez, E. Shafirovich. Hydrolysis of $\mathrm{CuCl} 2$ in the $\mathrm{Cu}-\mathrm{Cl}$ thermochemical cycle for hydrogen production: Experimental studies using a spray reactor with an ultrasonic atomizer. Int J Hydrogen Energy 2010; 35:1895-904.

[7] M.A. Lewis, J.G. Masin. The evaluation of alternative thermochemical cycles-Part II: The down-selection process. Int J Hydrogen Energy 2009; 34:4125-35.

[8] V. Daggupati, G.F. Naterer, K. Gabriel, R. Gravelsins, Z. Wang. Equilibrium conversion in $\mathrm{Cu}-\mathrm{Cl}$ cycle multiphase processes of hydrogen production. Thermo Acta 2009; 496:117-23.

[9] V. Daggupati, G. Naterer, K. Gabriel, Diffusion of gaseous products through a particle surface layer in a fluidized bed reactor, Int. J. Heat Mass Transfer. 53 (2010) 2449-2458. 
[10] T.O. Salmi, J. Mikkola, J.P. Warna, Chemical Reaction Engineering and Reactor Technology, CRC Press, Taylor and Francis Group, Boca Raton, FL, 2011.

[11] V. N. Daggupati, G. F. Naterer, I. Dincer, Convective heat transfer and solid conversion of reacting particles in a copper(II) chloride fluidized bed, Chemical Engineering Science 66 (2011) $460-468$

[12] M.A. Lewis, M.S. Ferrandon, D.F. Tatterson, P. Mathias, Evaluation of alternative thermochemical cycles-Part III further development of the $\mathrm{Cu}-\mathrm{Cl}$ cycle, Int. J. Hydrogen Energy. 34 (2009) 4136-4145. 
Table 1. Numerical simulation parameters

\begin{tabular}{|l|l|}
\hline Description & Quantity \\
\hline Particle diameter & $250 \mu \mathrm{m}$ \\
\hline Spray reactor pressure & $0.4 \mathrm{bar}$ \\
\hline Spray nozzle pressure & $24 \mathrm{bar}$ \\
\hline Density of $\mathrm{CuCl}_{2}$ slurry & $1.227 \mathrm{~g} / \mathrm{mL}$ \\
\hline Velocity at the tip of nozzle & $0.518 \mathrm{~cm} / \mathrm{s}$ \\
\hline
\end{tabular}

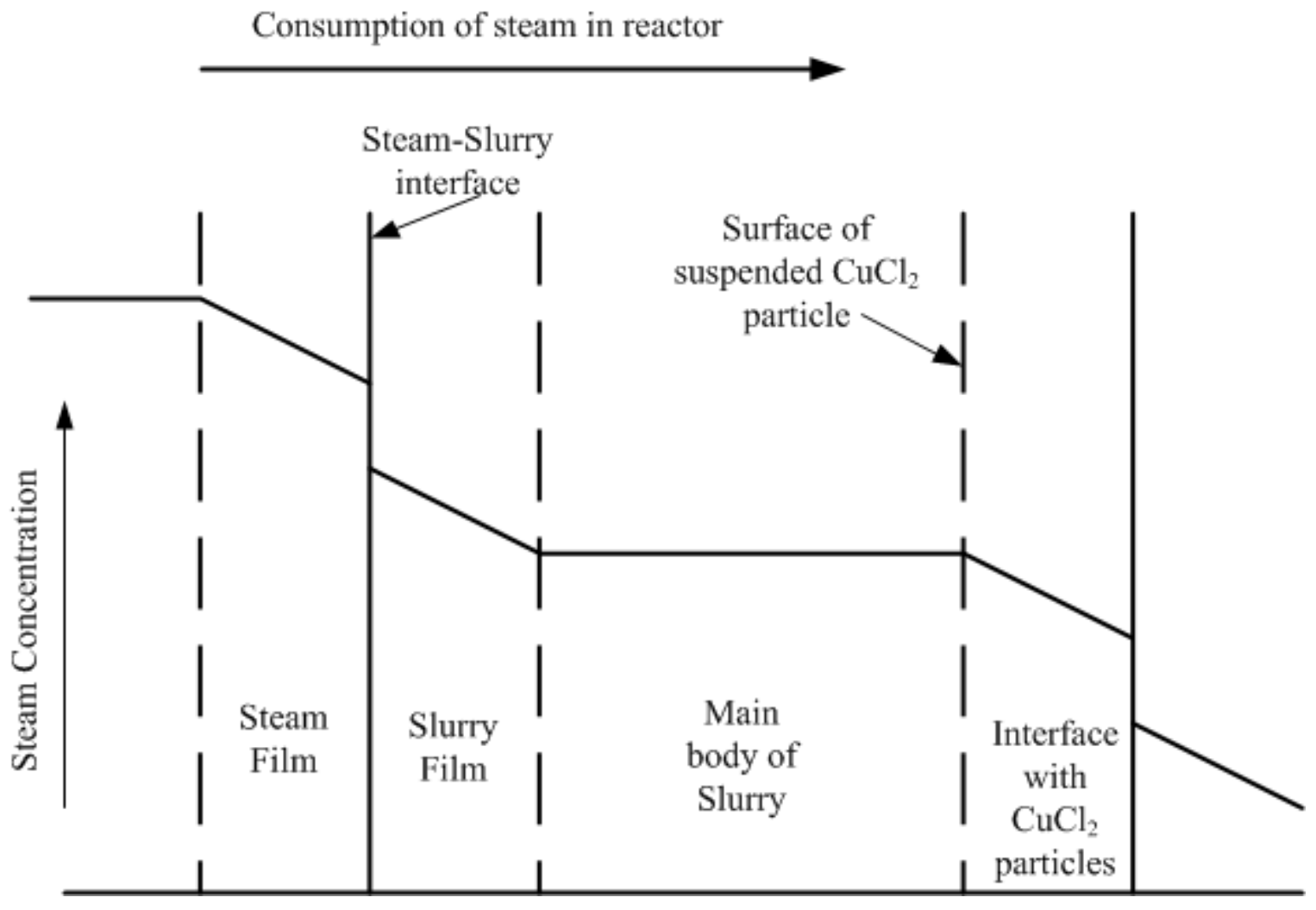

Figure 1: Reaction resistance in spray roaster for a droplet in the spray reactor 


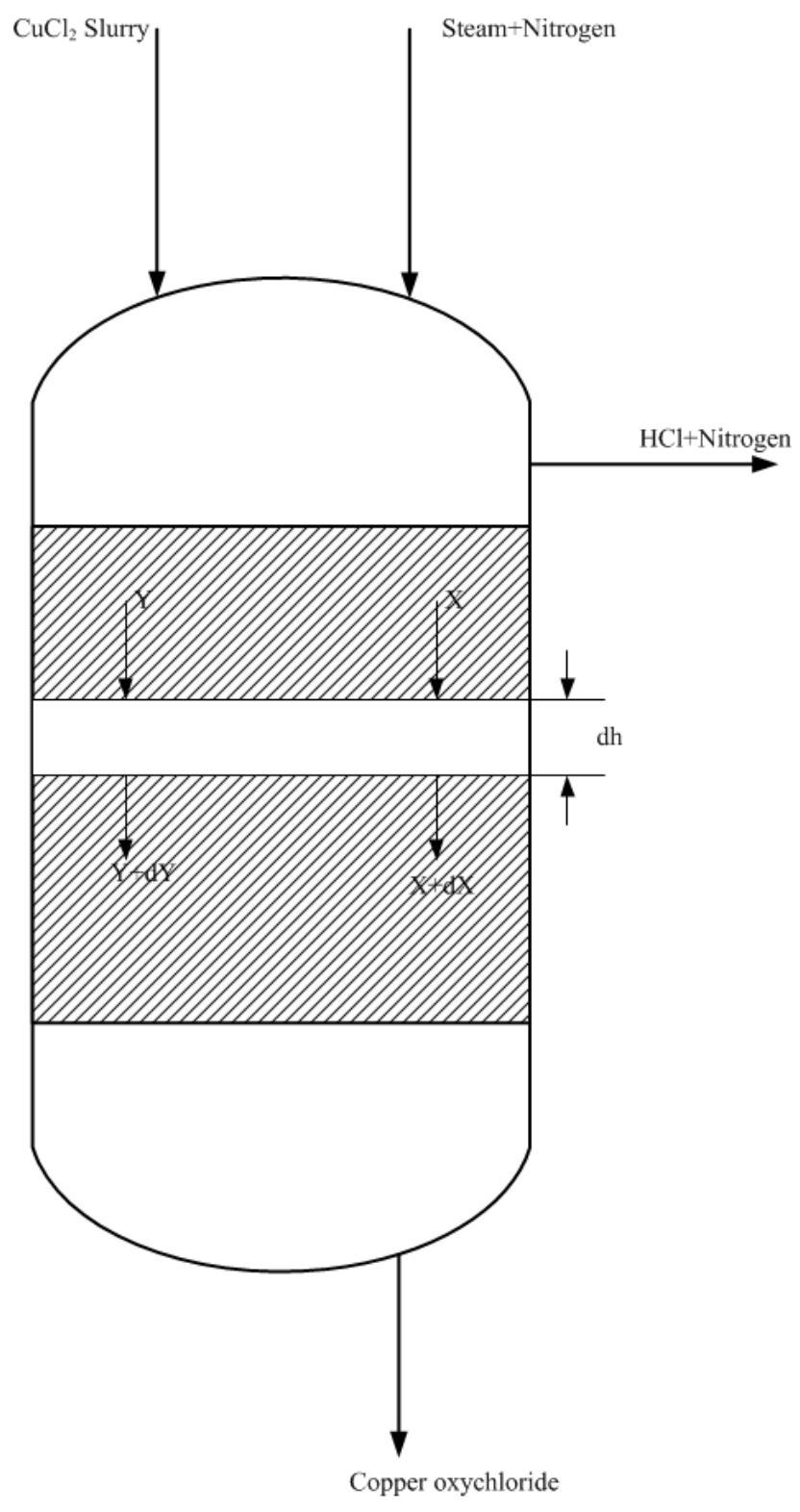

Figure 2: Schematic of spray reactor for producing copper oxy-chloride and $\mathrm{HCl}$ 


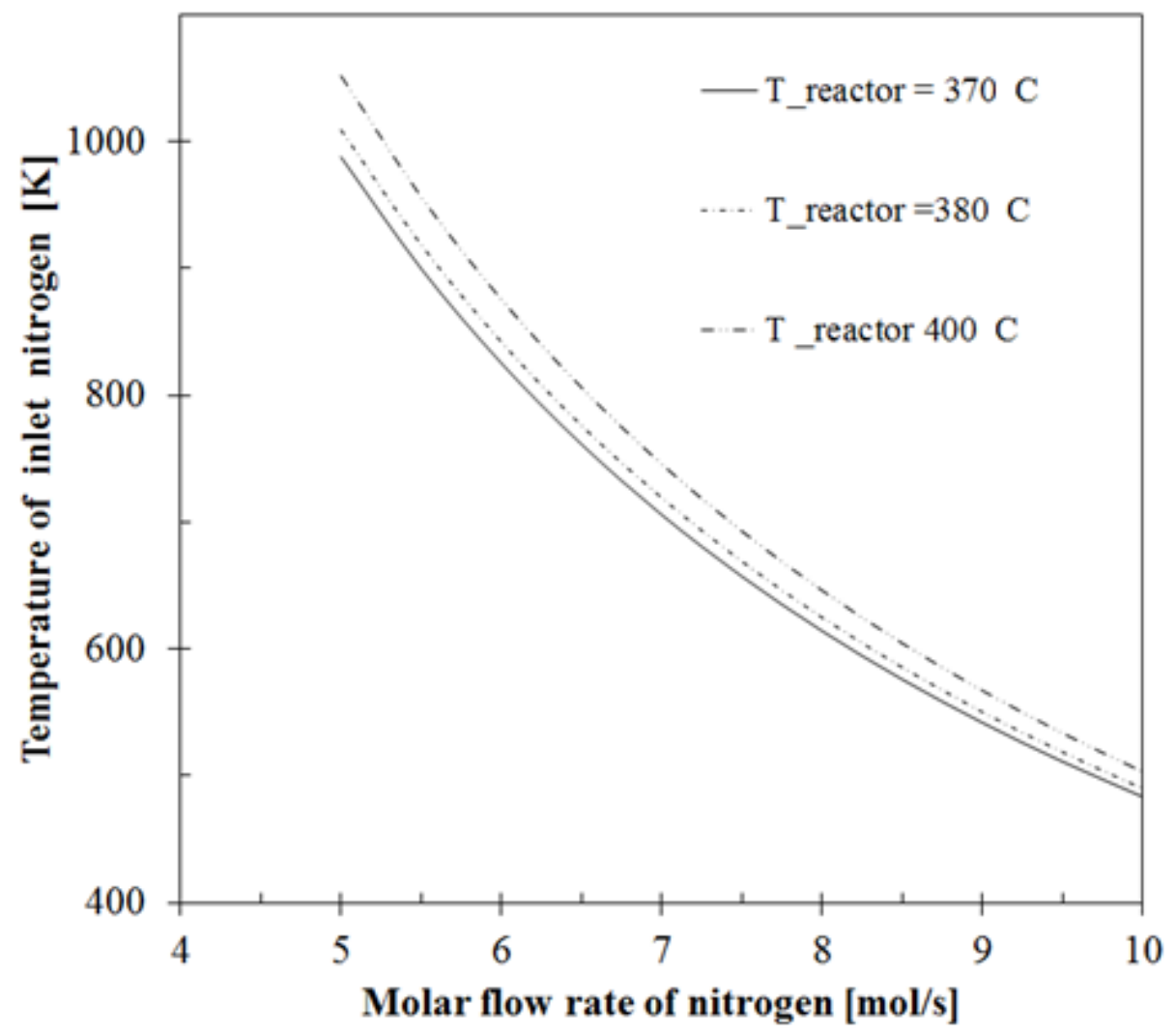

Figure 3: Effect of nitrogen temperature on molar flow rate 


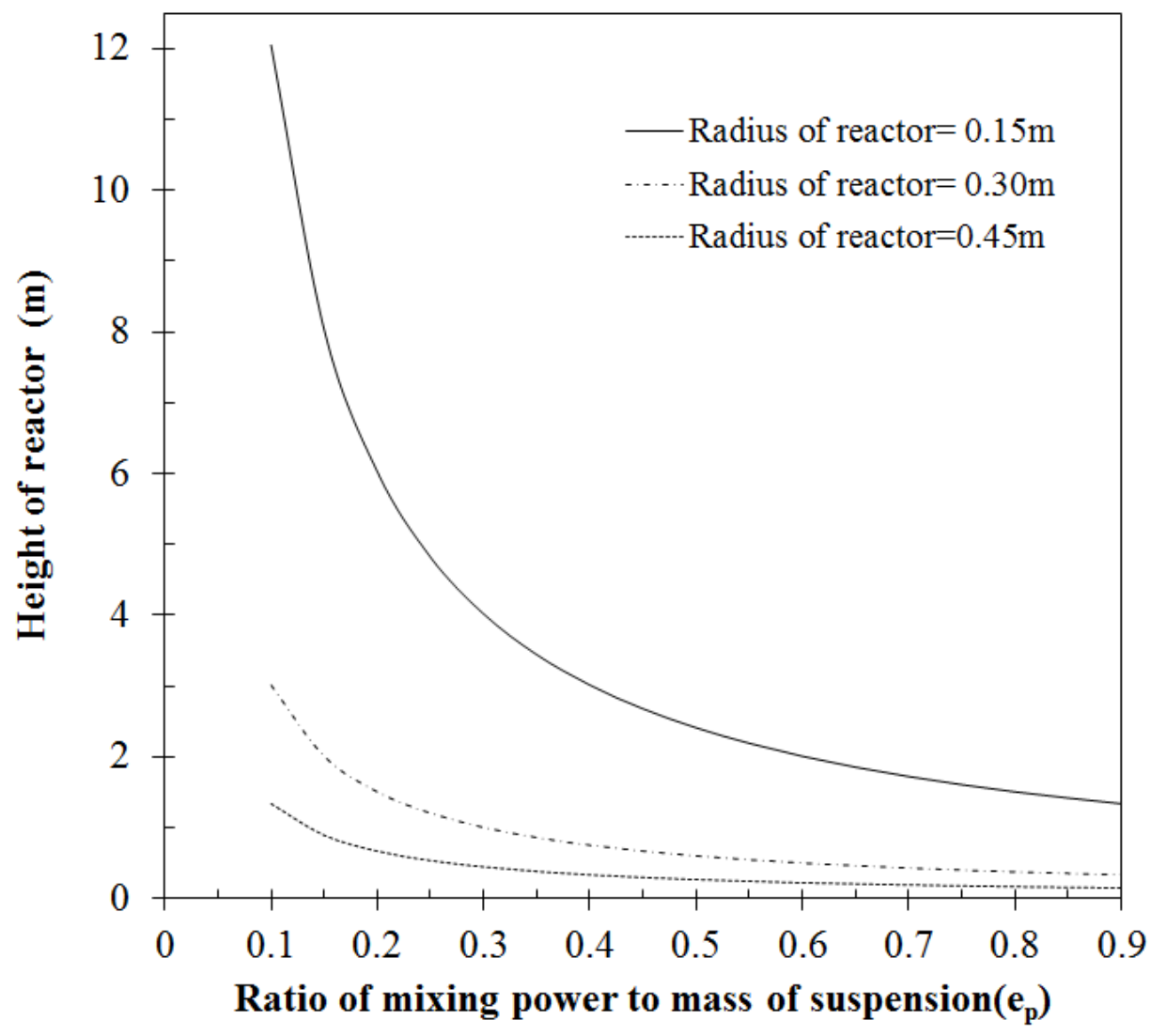

Figure 4: Effect of ratio of mixing power to mass of suspension on spray reactor height (production capacity of $3 \mathrm{~kg} \mathrm{H}_{2} /$ day) 


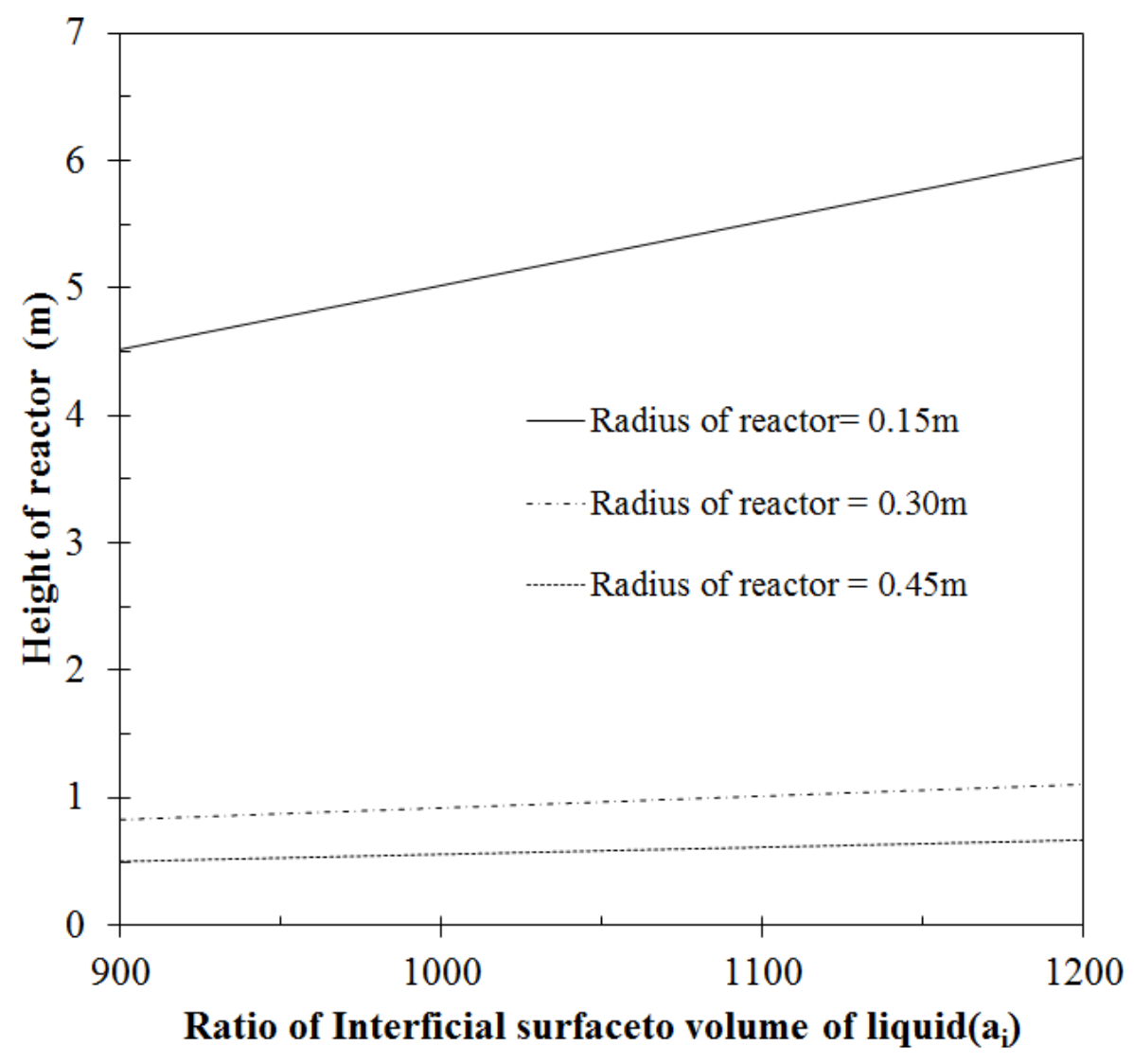

Figure 5: Effect of interfacial surface area of steam film to volume of the slurry injected into the spray reactor 


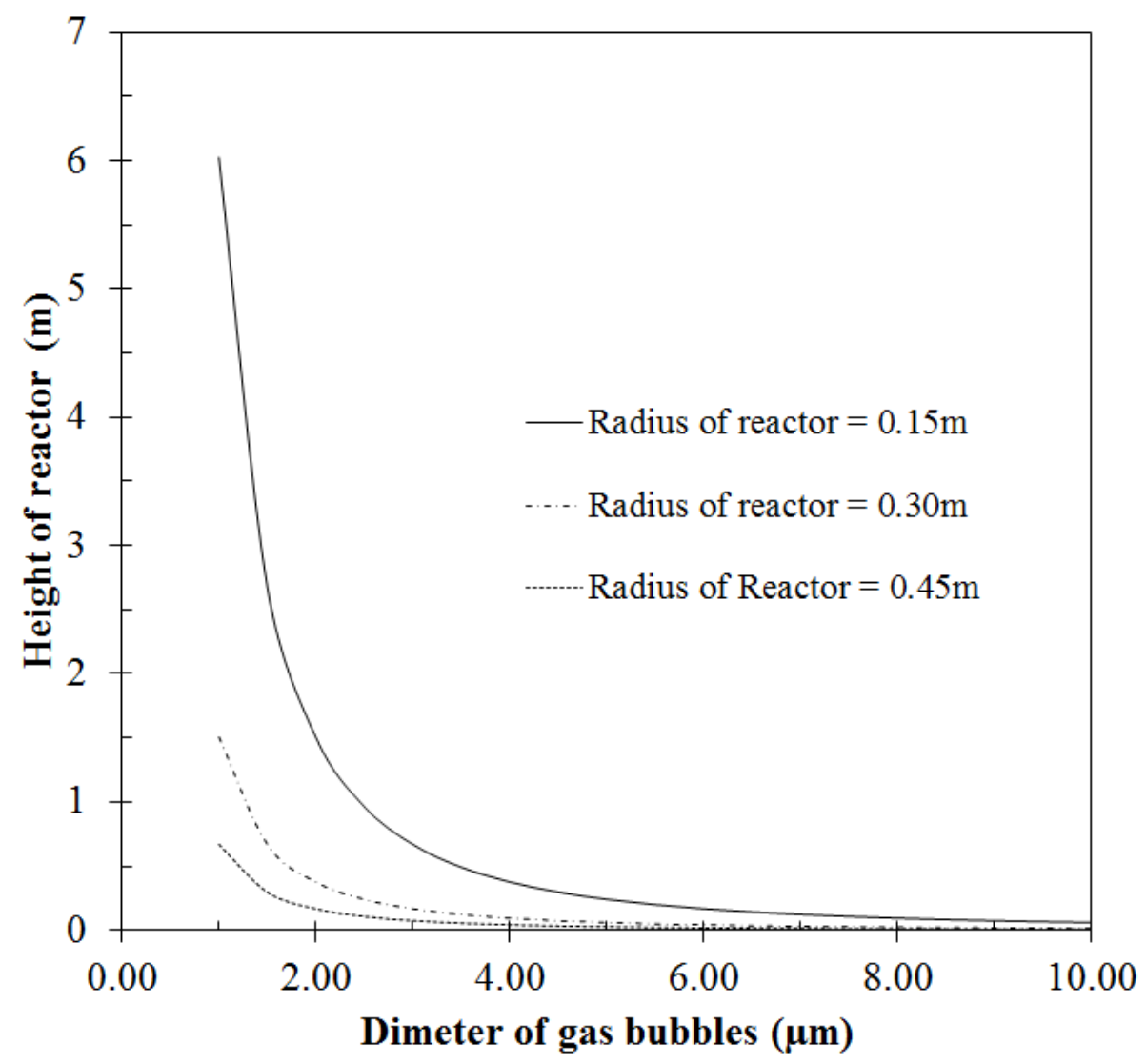

Figure 6: Effect of injected steam bubble diameter on height of spray reactor for a fixed particle diameter 